\title{
Synaptic Action of the Olivocerebellar System on Cerebellar Nuclear Spike Activity
}

\author{
Timothy A. Blenkinsop and Eric J. Lang \\ Department of Physiology and Neuroscience, New York University School of Medicine, New York, New York 10016
}

Cerebellar output is necessary for the ideal implementation of many nervous system functions, particularly motor coordination. A key step toward understanding the generation of this output is characterizing the factors that shape the activity of the cerebellar nuclei $(\mathrm{CN})$. There are four major sources of synaptic input that modulate $\mathrm{CN}$ activity; collaterals of climbing and mossy fibers are two, and the remaining two are provided by Purkinje cell (PC) axons in the form of simple spikes (SSs) and complex spikes (CSs). Most hypotheses of cerebellar function focus on SSs as the primary determinant of $\mathrm{CN}$ activity. However, it is likely that CSs also cause significant direct effects on $\mathrm{CN}$ activity, something that is rarely considered. To explore this possibility, we recorded from synaptically connected PC-CN neuron cell pairs in rats. Cross-correlograms of CS and CN activity from such recordings demonstrate that spontaneous CSs have a strong inhibitory effect on $\mathrm{CN}$ activity, apparently sufficient, in some cases, to trigger changes in the intrinsic excitability of the $\mathrm{CN}$ neuron that long outlast the underlying CS-mediated GABAergic IPSP. Furthermore, many CS-CN correlograms show an initial excitatory response, demonstrating the ability of climbing fiber collaterals to significantly excite $\mathrm{CN}$ neurons. A substantial fraction (24\%) of correlograms displayed an excitation-inhibition sequence, providing evidence that a $\mathrm{CN}$ neuron often receives collaterals from the same olivocerebellar axons as innervate the PCs projecting to it. Thus, excitation followed by inhibition appears to be a hard-wired response pattern of many $\mathrm{CN}$ neurons to olivocerebellar activity.

\section{Introduction}

The cerebellar nuclei $(\mathrm{CN})$ are the major conduit for activity flowing out of the cerebellum, giving them a central role in cerebellar function and making it critical to understand how their activity is modulated by synaptic input. Most $(\sim 70 \%)$ synaptic terminals on CN neurons arise from Purkinje cells (PCs) (Palkovits et al., 1977; De Zeeuw and Berrebi, 1995), suggesting that PC activity should be the dominant synaptically related factor shaping $\mathrm{CN}$ firing. However, even with the knowledge that PCs are inhibitory (Ito and Yoshida, 1966a; Ito et al., 1970), the transformation of PC activity into $\mathrm{CN}$ firing is not straightforward, in part because PCs display two types of spikes [simple spikes (SSs) and complex spikes (CSs)] and the specific effect of each of these on CN neurons is not known. Interactions between SSs and CSs further complicate the issue (Granit and Phillips, 1956; Bloedel and Roberts, 1971; McDevitt et al., 1982).

SSs are generally assumed to represent the significant output of the PC to the CN even though both CSs and SSs result in spikes that propagate down the PC axon (Ito and Simpson, 1971; Khaliq and Raman, 2005; Monsivais et al., 2005). If the effect of CS

\footnotetext{
Received June 30, 2011; revised Aug. 12, 2011; accepted Aug. 18, 2011.

Author contributions: E.J.L. designed research; T.A.B. performed research; T.A.B. and E.J.L. analyzed data; T.A.B. and E.J.L. wrote the paper.

This work was supported by grants to E.J.L. from the NIH (NS037028 and AA016566), National Science Foundation (I0S-1051858), and Irma T. Hirschl/Monique Weill-Caulier Trust.

The authors declare no competing financial interests.

Correspondence should be addressed to Dr. E. J. Lang, Department of Physiology and Neuroscience, New York University School of Medicine, 550 First Avenue, New York, NY 10016. E-mail: eric.lang@nyumc.org.

DOI:10.1523/JNEUROSCI.3323-11.2011

Copyright $\odot 2011$ the authors $\quad 0270-6474 / 11 / 3114708-13 \$ 15.00 / 0$
}

activity is considered at all, it is generally assumed that CSs act indirectly, either via short-term changes in SS activity, such as the post-CS pause and the postpause modulation of SSs (Granit and Phillips, 1956; Bloedel and Roberts, 1971; McDevitt et al., 1982), or as a mechanism underlying long-term synaptic plasticity.

That CSs would have no significant direct action on $\mathrm{CN}$ activity is paradoxical in that it implies that the most powerful excitatory synapse in the mammalian CNS does not function in any important way as a traditional excitatory synapse (i.e., to increase the probability of axonic spikes) or that the resulting spikes have no postsynaptic effect of consequence. A more important problem with the assumption of SS dominance is that the inhibitory nature of the PC implies an inverse relationship between SS and $\mathrm{CN}$ firing rates should exist if SSs are the primary modulator of $\mathrm{CN}$ activity, but such a relationship is often not found during motor behaviors as diverse as locomotion, wrist flexion, and saccades (Thach, 1970; Armstrong and Edgley, 1984a,b; Robinson and Fuchs, 2001). Furthermore, SS activity from individual PCs appears to have a negligible effect on $\mathrm{CN}$ neurons unless driven by a synchronizing input (Bengtsson et al., 2011).

If SSs are not the primary modulator of $\mathrm{CN}$ activity during behavior, relatively few alternatives exist. They include (1) collaterals of cerebellar afferents, (2) local CN circuits (interneurons and collaterals of projection cells), and (3) CSs. Although the first two possibilities surely contribute to $\mathrm{CN}$ output, the numerical dominance of PC synapses suggests that CSs may be an overlooked factor for determining $\mathrm{CN}$ activity. There are several difficulties in assessing this possibility, one of which is that PCs and $\mathrm{CN}$ neurons both show diverse responses during behavior, making it hard to determine their relationship by recording individ- 
ual cells in separate experiments and then comparing statistical measures of the two populations. To overcome this problem, we identified synaptically connected PC-CN cell pairs and investigated the effect of CSs of these PCs on the firing patterns of their target $\mathrm{CN}$ neurons.

\section{Materials and Methods}

Experiments were performed in accordance with the National Institutes of Health Guide for the Care and Use of Laboratory Animals. Experimental protocols were approved by the Institutional Animal Care and Use Committee of New York University School of Medicine.

\section{General surgical procedures and implantation of multiple electrode array}

Female Sprague Dawley rats (225-300 g) were anesthetized with an intraperitoneal injection of ketamine $(100 \mathrm{mg} / \mathrm{kg})$ and xylazine $(8 \mathrm{mg} / \mathrm{kg})$. Supplemental anesthesia (ketamine, $\sim 260 \mu \mathrm{g} \mathrm{kg}^{-1} \mathrm{~min}^{-1}$; xylazine, $\sim 50 \mu \mathrm{g} \mathrm{kg}^{-1} \mathrm{~min}^{-1}$ ) was given as a continuous infusion via a femoral vein catheter starting $\sim 2 \mathrm{~h}$ after the initial ketamine/xylazine dose. The exact rate of supplemental anesthesia was calibrated to prevent spontaneous and reflex movements and then kept constant throughout the recording sessions. Rectal temperature was maintained at $\sim 37^{\circ} \mathrm{C}$ by an electric heating pad. Animals were mechanically ventilated and given supplemental oxygen when necessary. After anesthetization, insertion of a femoral catheter, and tracheotomy, the head of the animal was fixed in a stereotaxic apparatus. The cerebellar cortex was exposed by removal of the overlying bone and dura mater and then covered by a platform that was cemented in place over crus $2 \mathrm{a}$. The platform consisted of an electron microscope grid embedded in silicone rubber and fixed to tungsten metal rods with epoxy and served to hold the microelectrodes in place and guide their spacing. Microelectrodes consisted of glass pipette tips $(3 \mathrm{~mm}$ long; $2-3 \mu \mathrm{m}$ tip diameter) filled with a $\mathrm{NaCl} /$ glycerol solution. A platinum-iridium wire was inserted into the base of the tip to connect it to the amplifier system. Microelectrodes were implanted into the cerebellar cortex using a joystick-controlled piezoelectric micromanipulator (EXFO Burleigh Products Group). Each microelectrode was attached to the micromanipulator via a wax droplet and pushed through a silicone rubber-filled hole in the grid and down $\sim 100 \mu \mathrm{m}$ into the molecular layer of the cerebellum until CS activity was isolated. The electrode was then released by melting the wax, and the next electrode was attached to the holder and similarly implanted. This process continued until an $\sim 4 \times 10$ array of electrodes with an interelectrode spacing of $250 \mu \mathrm{m}$ was implanted into an $\sim 1.7 \mathrm{~mm}^{2}$ area of crus $2 \mathrm{a}$. It is worth noting that at a depth of $100 \mu \mathrm{m}, \mathrm{CSs}$ are easily isolated and SS activity is not present, as the electrodes are in the molecular layer and therefore far from the PC somata.

\section{Deep cerebellar nuclei recording}

A capillary glass microelectrode was pulled using a model PE-21 glass puller (Narishige). The microelectrode was filled with a $\mathrm{NaCl} /$ glycerol solution. After implantation of the multielectrode array, the $\mathrm{CN}$ electrode was inserted into lobule crus 1 at an angle perpendicular to its surface $\pm 15^{\circ}$ and lowered to a depth of $\sim 3.0-3.5 \mathrm{~mm}$ using a stereotaxic micromanipulator (David Kopf Instruments). Starting at this depth, CN cells were searched for until the electrode reached a depth of $\sim 4.5 \mathrm{~mm}$. Recording tracks were made at various mediolateral distances (1.5-3.0 $\mathrm{mm}$ ) from the midline to attempt to record from cells from the fastigial, interpositus, and dentate nuclei because portions of crus 2a project to each of these nuclei.

\section{Multielectrode recording system and data acquisition}

The multielectrode recording system (MultiChannel Systems) consisted of 128 amplifier channels (total gain, $1000 \times$ ) with bandpass filters of 200 $\mathrm{Hz}$ to $8 \mathrm{kHz}$. Data were recorded onto a dual-processor personal computer using MultiChannel Systems MCRack data acquisition software (sampling rate, $20-25 \mathrm{kHz} / \mathrm{channel}$ ). This software allowed a voltage threshold to be set for each channel, the crossing of which was detected as an event. On detection of a threshold crossing, the system recorded the time and waveform of the voltage record, which were then used for off-line spike sorting and data analysis. For CSs, the threshold was set to detect the initial deflection of the CS, and a dead time (or blanking period) of $30 \mathrm{~ms}$ was used to ensure that each CS was counted only once.

In general, the CSs were well enough isolated that the single voltage threshold was sufficient to discriminate the spikes from baseline noise. Typically, CSs were 3-5 times baseline noise (Fig. 1 $A$ ) but occasionally could be significantly larger (Fig. $1 B$ ). When off-line spike sorting was used, a template was created by averaging 10-20 characteristic CSs from the PC. This template was then used to select spikes using the criteria that $>95 \%$ of the waveform remained within 3 SDs of the average and that no part of the waveform was $>4$ SDs from the average.

The MCRack software had oscilloscope and spike event displays for monitoring activity. The latter display comprised a grid onto which the electrode array was mapped, such that each box in the grid corresponded to the relative location of the electrode in the brain. A box would flash when the voltage threshold in the corresponding channel was crossed and thereby provided a means for simultaneously monitoring the spike activity from all cells. Analyses were made only for CN cells that were recorded for at least $10 \mathrm{~min}$, although a typical recording lasted $20 \mathrm{~min}$.

\section{Off-line data analysis}

All data analyses were performed within IGOR (Wavemetrics) using custom-made routines. Student's $t$ test, paired or unpaired as appropriate, was used for comparison of population means.

Cross-correlograms between CS and CN activity, with CSs acting as the trigger events, were constructed from the entire recording session and used to identify synaptic connectivity. For most additional analyses, only those CS-CN correlograms that had a relatively stable (horizontal) baseline before the CS ( $t=0 \mathrm{~ms})$ were used. However, as described in Results, a number of CS-CN correlograms had nonhorizontal baselines during the time preceding the $\mathrm{CS}$, indicating ongoing trends in the $\mathrm{CN}$ firing that were associated with the CS activity, but not directly caused by it (i.e., not a monosynaptic effect of the $\mathrm{CS}$ on the $\mathrm{CN}$ neuron being recorded). In these cases, it was of interest to investigate the effect of this network activity on the efficacy of the monosynaptic effects of CSs. To do this, the following procedure was used to select a subset of CSs in which baseline $\mathrm{CN}$ activity was relatively stable in the 300-500 ms before the CS occurrence. First, the start and stop times of a baseline trend in the correlogram from the entire recording were marked to define the time range of the trend. Then for each CS, the times of the CN cell spikes that fell within this range were determined. Each such $\mathrm{CN}$ spike was modeled as a unit Gaussian (area under curve $=1$ ) with a peak at the time of the spike relative to the start of the baseline trend and a width (standard deviation) of $5 \mathrm{~ms}$. The Gaussians for all CN spikes associated with a particular CS were summed to form a spike density function whose duration was defined by the difference in the start and stop times of the trend. Least squares regression was used to fit a line to this function to obtain $\beta$, the slope of the regression line. Once a $\beta$ was obtained for all CSs, they were ranked in ascending order of $|\beta|$, and the lowest 25 th to 50 th percentiles (those $\beta$ closest to zero) were used to select CSs. Trials in which no CN spikes occurred during the baseline period were excluded from the selection process. If more than one trend was present in the baseline period, an additional iteration of the above steps was performed to refine the subset of CSs further. In the present study, only one or two iterations were needed to obtain CS-CN correlograms with flat baseline periods. Once the CS selection process was completed, a CS-CN correlogram was constructed using just the selected CSs.

\section{Anatomical verification of $\mathrm{CN}$ neuron recording sites}

To allow anatomical verification of the locations of the presumed $\mathrm{CN}$ neurons, a small amount of alcian blue dye was injected to mark the position of the last cell recorded in an experiment (the recording solution was exchanged for one containing the dye while keeping the electrode in place). The micrometer reading of the depth of the injection was noted to allow for correction of shrinkage of the tissue with fixation. The animal was then perfused with saline followed by $10 \%$ formalin. The brain was removed, soaked in $10 \%$ formalin for 1-2 d, and transferred to a $30 \%$ sucrose $/ 10 \%$ formalin solution until it sank. Transverse $60 \mu \mathrm{m}$ crosssections of the cerebellum were prepared on a freezing microtome and counterstained with cresyl violet. 
The approximate locations of other presumed $\mathrm{CN}$ cells were determined by calculating their positions relative to the alcian blue marked site using the difference in stereotactic coordinates from the marked site after adjustment for shrinkage of the tissue with fixation. Cell locations were then plotted on the most closely matched coronal section from a standard rat brain atlas (Paxinos and Watson, 1998). Although only approximate, almost all cells were located within the boundaries of the $\mathrm{CN}$ with the remainder located in the immediately adjacent white matter, consistent with their being $\mathrm{CN}$ neurons.

\section{Results}

To characterize the synaptic action of the olivocerebellar system on CN spike activity, we performed experiments in which CSs were recorded from an array of PCs simultaneously (20.5 PCs, on average; range, 8-34 PCs) along with the activity of one to two CN cells. In total, 717 PCs and $100 \mathrm{CN}$ cells were recorded in 35 rats. All PCs were located on the apex of crus $2 \mathrm{a}$. The recording array was up to $2.25 \mathrm{~mm}$ in length in the mediolateral direction (along the longitudinal folial axis), with its medial border located just (0- $1 \mathrm{~mm})$ lateral to the paravermal vein. Based on a previous study, recorded PCs were thus likely located in zebrin-stained compartments 4a- to 6- (Sugihara et al., 2007). These compartments project to regions in all CN (Buisseret-Delmas and Angaut, 1993; Sugihara et al., 2009). Thus, in each experiment, electrode tracks through the $\mathrm{CN}$ were made in various parasagittal planes to cover territories ranging from the lateral part of the fastigial nucleus to the dentate nucleus in an attempt to find $\mathrm{CN}$ cells that were postsynaptic to the PCs being recorded.

\section{Stability of CS recordings}

The results presented below will be interpreted as showing a powerful inhibitory effect of CSs on the activity of CN neurons. Critical to this interpretation is that the recorded activity is truly CS activity from individual PCs, as opposed to fields generated by the summed activity of many synchronously active PCs. To demonstrate this is, in fact, the case, we show (1) that the detected waveforms were stable over the recording period, indicating that the same type of events were being recorded throughout, and (2) that these events are caused by single-cell CSs as opposed to fields resulting from synchronous activity.

To demonstrate the stability of the preparation, the average CS waveforms from the beginning and end of the recording session were compared for four experiments $(n=101 \mathrm{PCs})$. In almost all cases (95 of 101), the average CS waveform showed little to no change in waveform (Fig. $1 C-G$ ). In the remaining six cases, some changes in the initial spike or the trailing spikelets occurred (Fig. $1 \mathrm{H}$ ). However, even in these cases, the majority of the waveform remained quite similar throughout the recording session. It is worth noting that individual CSs from the same PC
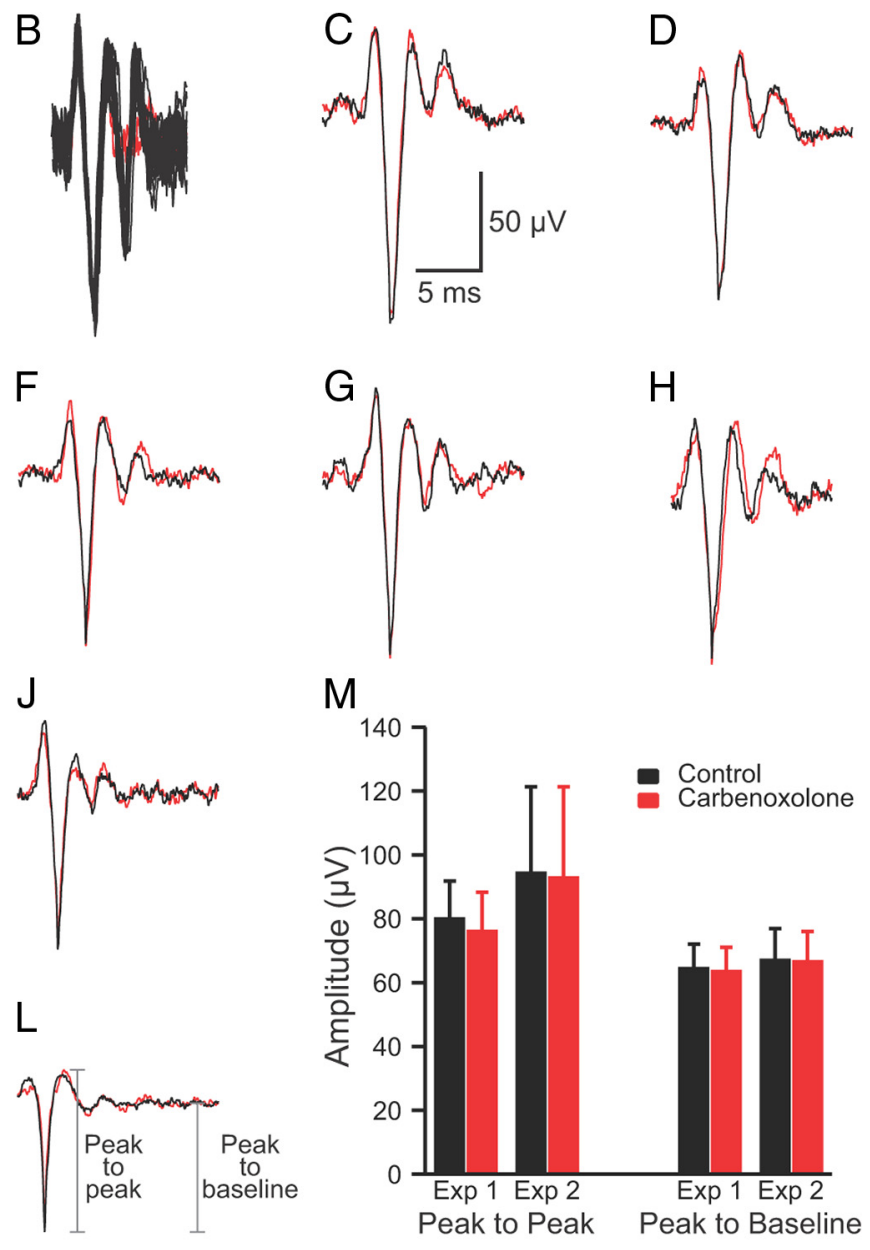

Figure 1. Characteristics of $C S$ recordings. $A, B$, Extracellularly recorded CS activity. Each panel shows 20 overlapped traces. In $\boldsymbol{B}$ the last spikelet of the CS failed to occur in two cases (red traces). Calibration bars in $\boldsymbol{A}$ are for $\boldsymbol{A}$ and $\boldsymbol{B}$. C $\boldsymbol{C}$, Average $\mathrm{CS}$ waveform (be ene elrode at the beginning (black) and the end (red) of the recording session. Approximately 50 traces are in each injection into the 10 (red). Averages are from $\sim 50(I, J)$ and $\sim 200(K, L)$ records. Calibration bars in $C$ are for $C-L . M$, Average amplitude of $(S$ waveform in control (black bars) and after desynchronization with carbenoxolone (red bars). Averages are of 11 PCs (Exp 1) and 16 PCs (Exp 2). Error bars are 1SD.

do vary somewhat (necessitating the use of averages). An example of this variability can be seen in the overlapped traces in Figure $1 B$, where in two cases (red traces) the last spikelet is missing despite the preceding portion of these spikes being identical to the other traces. Such variation in CS waveform has been demonstrated with intracellular recordings as well (Llinás and Sugimori, 1980a). Nevertheless, the constancy of the averages indicates that the same underlying events were being detected throughout the recordings.

\section{Recorded signals represent CSs generated from individual PCs, not field potentials caused by synchronized activity} Typically, the all-or-none behavior of spikes versus the graded nature of fields attributable to synchronous activity is the simplest way to distinguish the two types of phenomena. This approach is somewhat problematic with CS activity, however, because CSs can vary somewhat instance to instance (Fig. 1B; Llinás and Sugimori, 1980a), mostly likely because they propagate over a branched dendritic tree, the degree of invasion of which may vary. Thus, a different approach was used in which the effect of desynchronizing CS activity on the average waveform was measured. If the recorded events are fields attributable to 
synchronized activity, they should be reduced in size in proportion to the degree of desynchronization. As we reported previously, injections of carbenoxolone, a gap junction blocker, into the inferior olive (IO) reduce CS synchrony (Blenkinsop and Lang, 2006). We chose two experiments ( $n=27$ PCs) from that data set in which the carbenoxolone injection produced large reductions in CS synchrony (81 and 93\%) and compared the average CS waveform recorded by individual electrodes before the injection and after carbenoxolone had reduced CS synchrony. Almost no change was found in the average waveforms between the two conditions. Figure $1 I-L$ shows examples of average CSs from the two conditions. Measurement of spike amplitude (peak to peak or peak to baseline) verified the relative constancy of the waveforms across the conditions (Fig. 1M). Average amplitudes for the two experiments combined were as follows: peak to peak: control, $89.0 \pm 22.6 \mu \mathrm{V}$; carbenoxolone, $86.5 \pm 24.0 \mu \mathrm{V}$; peak to baseline: control, $66.4 \pm 8.5 \mu \mathrm{V}$; carbenoxolone, $65.9 \pm 8.2 \mu \mathrm{V}$. It should be noted that a small percentage reduction in amplitude between control and carbenoxolone was present (2.7 and $0.8 \%$, measured peak to peak and peak to baseline, respectively). This difference was only significant for the peak-to-peak measurements using a paired $t$ test $(p=0.027)$, suggesting a small consistent difference that might reflect the contribution of fields attributable to synchronous activity. Nevertheless, this reduction is far less than would be expected if fields from synchronized activity were the major component of the waveform, given the large reduction in CS synchrony caused by carbenoxolone. Thus, the waveforms recorded by each electrode can be primarily attributed to the CS activity of an individual PC.

Consistent with the above results and conclusion, a similarly small effect of synchronization on CS waveform (recorded using the same technique) can be seen by comparing spontaneous CS activity with that evoked by stimulation of the IO [Sugihara et al. (1993), their Fig. 1C]. Because of the topography of the olivocerebellar projection, such stimuli should evoke highly synchronous CS activity among neighboring PCs, which should result in much larger-amplitude responses being observed if the recorded signals represented fields generated by synchronously active PCs. In contrast, overlap of the evoked and spontaneous CS activity shows only minor differences. Thus, the same conclusion (i.e., what is being recorded with our technique are the CSs of individual PCs) can again be drawn.

A final line of evidence that single-cell CSs are being recorded is that when lowering an electrode in search of an optimal signal, the electrode, on occasion, will penetrate a PC dendrite (as evidenced by a high-frequency discharge of spikes of rapidly diminishing amplitude) resulting in the loss of the CS activity that had been present. This sudden disappearance of the CS signal with local damage is consistent with it being from a single PC, but not with it being a field generated by many synchronized PCs.

Thus, the signals we recorded in the molecular layer represent dendritic CSs from individual PCs. Note that these spikes are likely distinct entities from the somatic spikes triggered by the same climbing fiber (CF) activity, because somatic spikes do not propagate well into the PC dendritic tree (Llinás and Nicholson, 1971b; Llinás and Sugimori, 1980b; Stuart and Hausser, 1994), PC dendrites have the intrinsic ability to generate spikes (Llinás and Nicholson, 1971a,b; Llinás and Sugimori, 1980b), and the generation of dendritic and somatic CSs can be experimentally decoupled (Davie et al., 2008). Nevertheless, there is a direct correspondence between the occurrence of the dendritic CSs and the somatic ones that trigger the axonic spikes, as both are triggered without fail by climbing fiber activity.

\section{Properties of $\mathrm{CN}$ cell activity under ketamine/xylazine anesthesia}

$\mathrm{CN}$ neurons displayed a wide range of firing rates (Fig. $2 A$ ), with an overall mean rate of $45.3 \pm 21.4 \mathrm{~Hz}$. In addition to varying considerably in their average firing rates, $\mathrm{CN}$ neurons displayed a range of firing patterns, from a bursting pattern in which periods of firing alternated with extended silences (Fig. 2C) to one in which there was essentially tonic activity (Fig. $2 D$ ), as has been described (Rowland and Jaeger, 2005). Most CN cells ( $n=86$ of 100 ) in our experiments had a burst-type firing pattern, based on examination of the raw recordings and interspike interval (ISI) histograms. The burst pattern was typified by a long rightward tail in the ISI distribution (Fig. $2 E-G$ ). Tonically firing cells, such as the one in Figure $2 D$, were distinguished by histograms that lacked the tail portion of the ISI distribution ( $n=14$ of 100; Fig. $2 H$ ). The cycling between burst and silent periods exhibited some regularity in many cells (usually with a period between 0.5 and $1 \mathrm{~s}$ ), but the relative amount of time spent in the active (burst) state varied considerably among cells, reflecting variations in both burst and pause durations, and, indeed, some cells showed patterns intermediate between the burst and tonic categories, making these categories ends of a spectrum of firing patterns. ISI histograms not only distinguished burst and tonic firing categories but also subtypes of burst firing cells (Fig. $2 E-G$ ). In some cases $(n=25$ of 86$)$, the ISI histograms for burst-type cells displayed a secondary (and rarely a tertiary) peak in the ISI histogram riding on the tail between 100 and $400 \mathrm{~ms}$, reflecting a preferred pause duration (Fig. $2 E, F)$. In most cases $(n=61$ of 86), however, no clear second peak was observed (Fig. 2G). Although the presence of a tail was used to distinguish burst and tonic firing patterns, the primary peak (modal ISI) also seemed to vary between the two firing patterns. For the $\mathrm{CN}$ population as a whole, the primary peak in the ISI histograms averaged $11.7 \pm$ $10.3 \mathrm{~ms}$. The modal ISI of burst firing cells appeared to be shorter and less variable $(10.2 \pm 5.6 \mathrm{~ms})$ than that of tonic firing cells $(20.9 \pm 22.2 \mathrm{~ms})$; however, the difference in means was not statistically significant $(p=0.099)$.

Like the pauses, bursts showed considerable variability in their characteristics, both between cells and between bursts of a single cell. The instantaneous frequency during a burst could increase, decrease, or remain relatively constant. Moreover, the average firing rate during different bursts of the same cell could vary by tens of hertz. Individual tonically firing cells also showed considerable variation in their firing rate (Fig. $2 D$ ).

\section{Identification of synaptic connectivity between PCs, CFs, and $\mathrm{CN}$ neurons}

To study the effect of olivocerebellar activity on CN neurons, we sought to identify PCs that were presynaptic to the $\mathrm{CN}$ cell being recorded. To do this, we generated cross-correlograms of CS and $\mathrm{CN}$ activity that were triggered off of the CSs (CS-CN correlograms) and looked for evidence of monosynaptic connectivity (described in the next paragraph). In addition, because of the one-to-one relationship between an action potential in a CF and the CS in a PC with which it synapses, CS-CN correlograms can also provide evidence of a monosynaptic connection between the $\mathrm{CF}$ that projects to the recorded $\mathrm{PC}$ and a $\mathrm{CN}$ neuron being recorded. [Note that because the somatic IO action potential has a large afterdepolarization, it often triggers a burst of several axonal spikes (Crill, 1970; Llinás and Yarom, 1981), but for the present purposes, this burst is considered as a single entity, because each such burst triggers only a single CS.] 


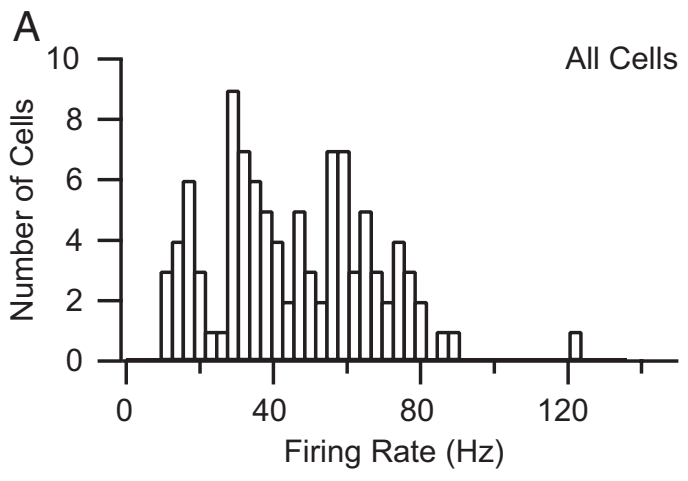

$\mathrm{C}_{1}$

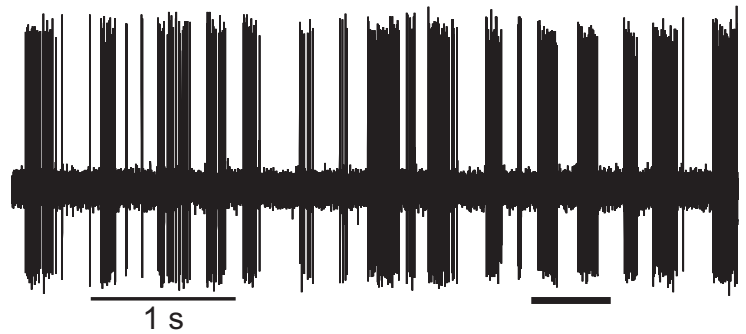

$\mathrm{D}_{1}$

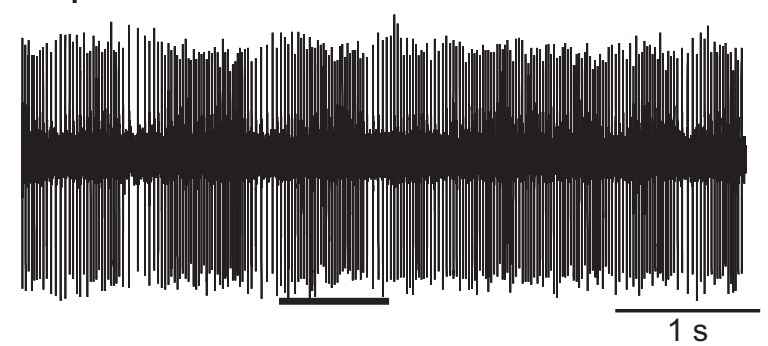

E

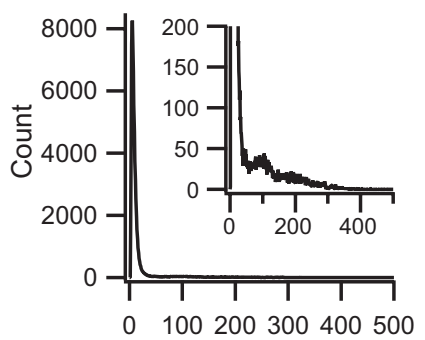

ISI (ms)
F

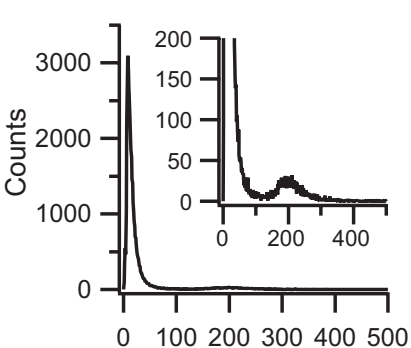

ISI (ms)
B

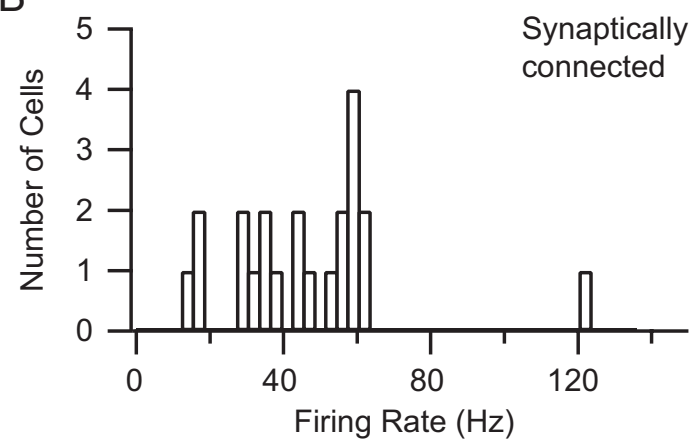

$\mathrm{C}_{2}$

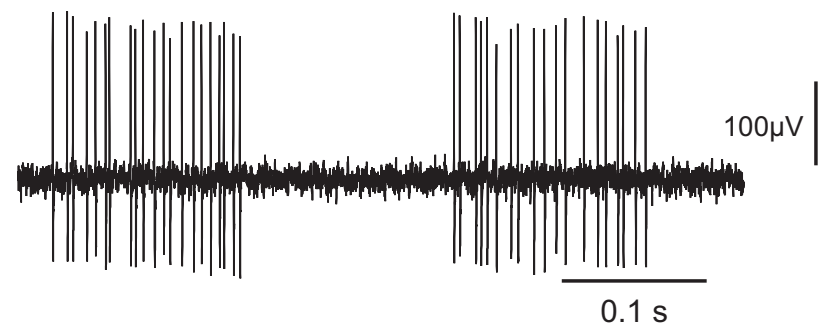

D2

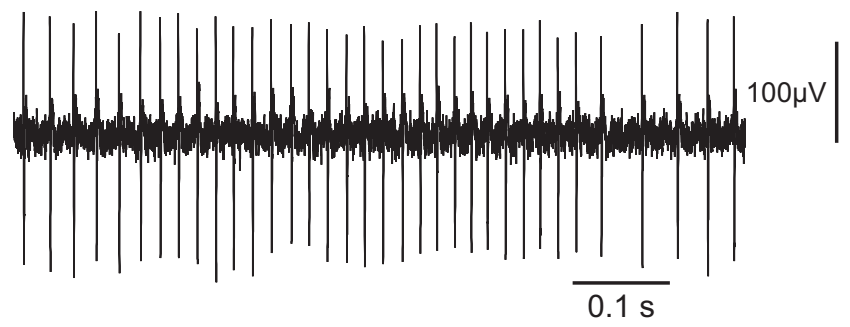

G

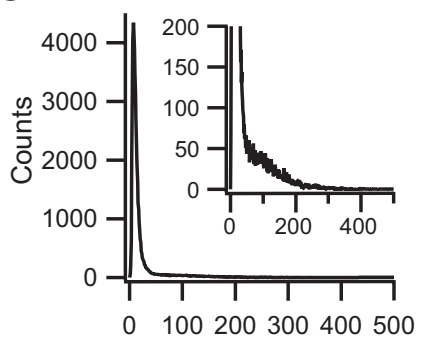

ISI (ms)
$\mathrm{H}$

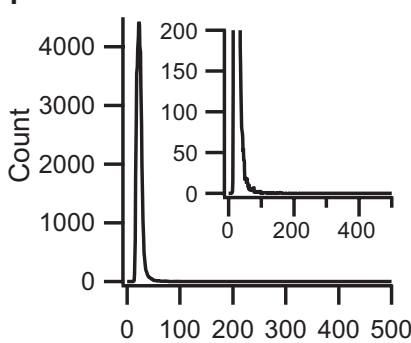

ISI (ms)

Figure 2. Firing patterns of $C N$ neurons. $\boldsymbol{A}, \boldsymbol{B}$, Histograms of $C N$ firing rates for the entire recorded population $(\boldsymbol{A})$ and for those $C N$ neurons identified as synaptically connected to recorded crus $2 \mathrm{a} \mathrm{PCS}(\boldsymbol{B})$. Firing rates typically represent the rate averaged over a $20-40$ min recording session. $\boldsymbol{C}, \boldsymbol{D}$, Extracellular recordings from $(\mathrm{N}$ neurons showing typical burst $(\boldsymbol{C})$ and tonic $(\boldsymbol{D})$ firing patterns. The segments indicated by the thick horizontal bars in $\boldsymbol{C}_{1}$ and $\boldsymbol{D}_{1}$ are shown at an expanded time scale in $\boldsymbol{C}_{2}$ and $\boldsymbol{D}_{2}$. Voltage calibration in $\boldsymbol{C}_{2}$ is also for $\boldsymbol{C}_{1}$, and that in $\boldsymbol{D}_{2}$ is also for $\boldsymbol{D}_{1} \cdot \boldsymbol{E}-\boldsymbol{H}$, Interspike interval (ISI) histograms from four cells showing the range of patterns observed. $\boldsymbol{E}-\boldsymbol{G}$, Examples of ISI histograms from burst firing $C \mathrm{CN}$ neurons. All show long rightward tails to their distributions. Some show a secondary peak $(\boldsymbol{E}, \boldsymbol{F})$ indicative of a preferred pause duration, but others do not $(\boldsymbol{G})$. The ISI in $\boldsymbol{E}$ is from the cell shown in $\boldsymbol{C}$. $\boldsymbol{H}$, ISI histogram from the tonically firing cell shown in $\boldsymbol{D}$.

There are three basic patterns of connectivity between a $\mathrm{CF}$, $\mathrm{PC}$, and $\mathrm{CN}$ neuron. The first pattern is a monosynaptic connection between the PC and the $\mathrm{CN}$ cell, as diagrammed schematically in Figure 3A. CS-CN correlograms of cells having this pattern should exhibit a sharp decrease at a short latency after the onset of the CS that reflects both the conduction time of the PC-CN pathway and the rise time of the IPSP in the CN cell (i.e., $\sim 1-5$ ms; Ito et al., 1970; Sastry et al., 1997). The second pattern is one in which monosynaptic connections to the $\mathrm{CN}$ cell are made by both a PC and a collateral of its CF
(Fig. 3B). In this case, the CS-CN correlogram should show an initial brief increase in activity followed by a negative deflection similar to that described for the first pattern. The exact onset of the initial positive deflection will depend on several factors (i.e., relative lengths and conduction velocities of the main and collateral branches of the CF axon), but in all cases, it cannot precede the CS by more than the conduction time of the olivocerebellar pathway, which is $\sim 5 \mathrm{~ms}$ in the rat (Sugihara et al., 1993). The third pattern occurs when the PC itself does not synapse with the $\mathrm{CN}$ cell being recorded but a collat- 


\section{A only PC connects to $\mathrm{CN}$ neuron}
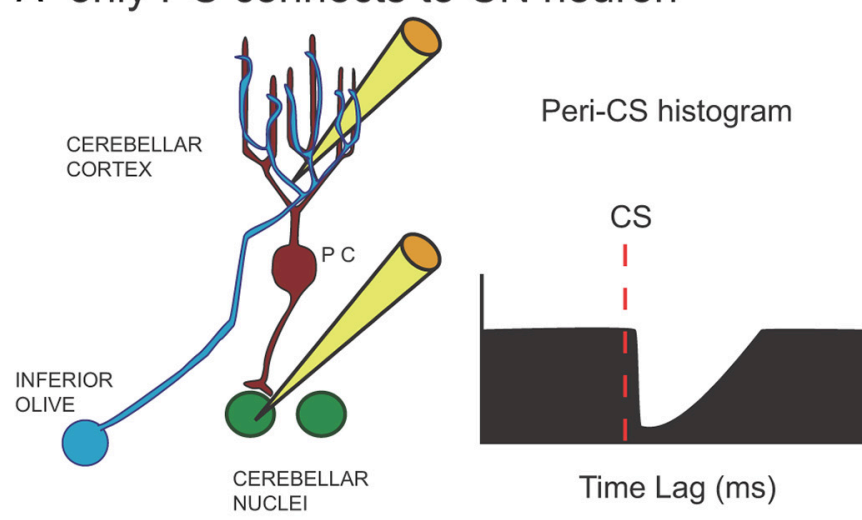

B $\mathrm{IO}$ axon and PC connect to $\mathrm{CN}$ neuron

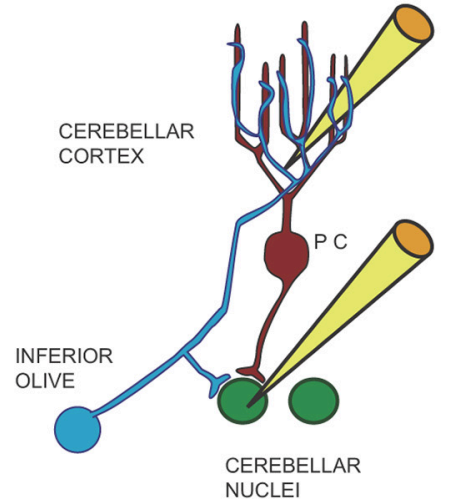

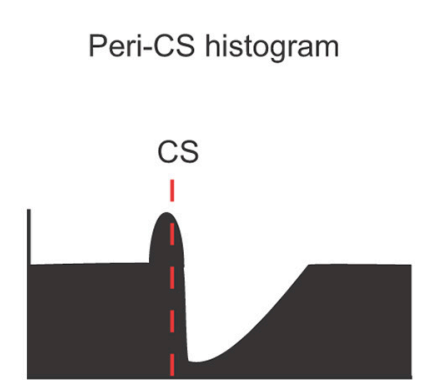

Time Lag (ms)

\section{C only $\mathrm{IO}$ axon connects to $\mathrm{CN}$ neuron}

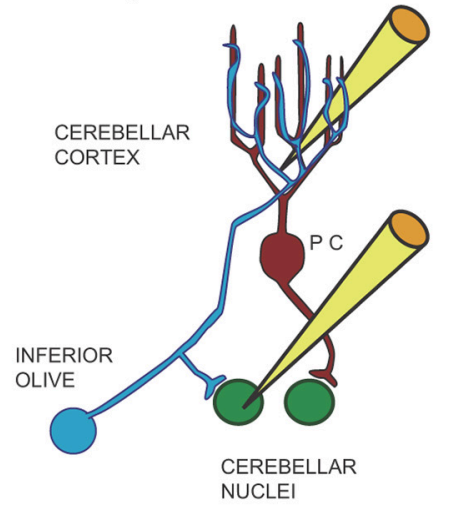

D 10 axon branching
Peri-CS histogram

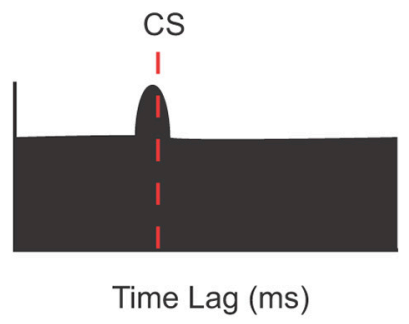

Time Lag (ms)
Peri-CS histogram

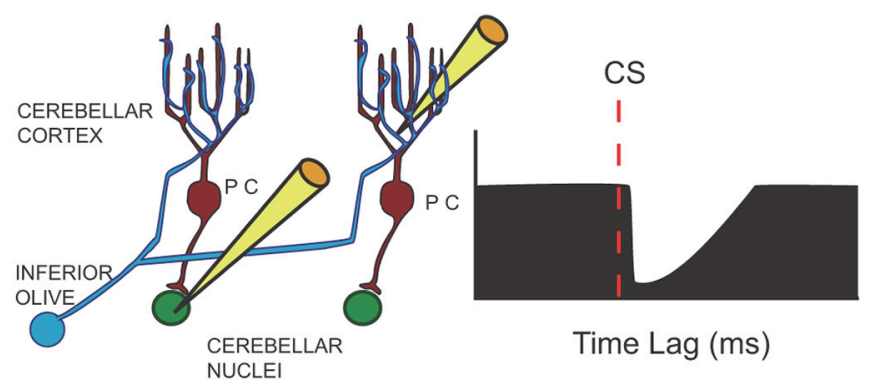

Figure 3. Schematic representation of basic connectivity patterns between 10 axon, $\mathrm{PC}$, and $\mathrm{CN}$ neuron. $A-C$, The three possible ways to connect an 10 axon, a recorded $\mathrm{PC}$, and a recorded $\mathrm{CN}$ neuron are shown along with schematic $C S-C N$ correlograms that each would be expected to produce. $\boldsymbol{D}$, An alternative connection pattern caused by the branching of 10 axons to multiple $P(s$ that would produce a similar CS-CN histogram as that shown in $A$. Yellow electrodes indicate which cells are being recorded.

eral of its $\mathrm{CF}$ does (Fig. 3C). In this case, just an initial positive deflection would be observed. It should be noted that the branching of IO axons to multiple PCs $(\sim 7$ in rat; Schild, 1970 ) means that the correlogram shown in Figure $3 A$ could also reflect the innervation of the $\mathrm{CN}$ cell by another of the PCs contacted by the same CF as innervates the PC being recorded (Fig. 3D). Analogous situations are also present with respect to the correlograms shown in Figure 3, $B$ and $C$. Nevertheless, in all of these situations, the correlograms reflect the monosynaptic action of PC CSs, and/or the monosynaptic action of IO axon collaterals, on the $\mathrm{CN}$ neuron.

We used the timings just specified, and the direction of the onset of a change in firing rate, as our primary criteria for identifying synaptic connections, because other parameters, such as the duration and amplitude of the change, likely depend more heavily on nonsynaptic factors, such as the intrinsic membrane properties of the $\mathrm{CN}$ neurons. In many cases, the CS-CN correlograms showed relatively flat horizontal baselines during the time just preceding the CS, like the schematics of Figure 3, making it straightforward to detect the onset of the excitatory or inhibitory changes. However, in other cases, the baseline of the CS-CN correlogram was sloped. In these cases, an appropriately signed significant change in the slope of the baseline at the appropriate latency was used as evidence of a synaptic connection. To assess whether the change in slope was significant (i.e., indicated a monosynaptic connection), a line was fit to short time segments relative to the CS, which corresponded to the baseline $(-10$ to $0 \mathrm{~ms}$ if no excitatory response was present, or -15 to
$-5 \mathrm{~ms}$ if one was) and to the onsets of the excitatory ( -5 to 0 $\mathrm{ms})$, if present, and inhibitory (3-13 ms) responses. A $t$ test was then used to test whether the slopes of the regression lines were significantly different (Zar, 1999).

Of the $100 \mathrm{CN}$ cells recorded, 22 were found to exhibit one of the above-described synaptic connectivity patterns with one or more PCs based on analysis of their CS-CN correlograms. In total, 100 of 1824 CS-CN correlograms showed evidence of synaptic connections (5.5\%). Of these 100, 33 correlograms (from eight $\mathrm{CN}$ cells) had flat baselines like those shown in Figure 4, $A$ and $B$, and 67 had modulated baselines (see Fig. 7A1,B1). The remaining CS-CN correlograms were either flat or showed one of a variety of patterns, but no specific change was detected at the precise latencies indicative of the synaptic connections described above (Fig. $4 C)$. Although the latter correlograms suggest the presence of complex interactions among neurons of the cerebellum and IO, they will not be considered further at present, as the focus here is on the monosynaptic effects of olivocerebellar activity on $\mathrm{CN}$ neurons.

$\mathrm{CN}$ neurons with identified synaptic connections $(n=22)$ had similar firing characteristics to the overall population. For example, the synaptically connected group of $\mathrm{CN}$ cells had a similar distribution of firing rates (Fig. $2 \mathrm{~B}$ ) as the overall population, with a mean firing rate $(46.3 \pm 22.7 \mathrm{~Hz})$ that was statistically the same as that of the larger population $(p=0.85)$. Moreover, evidence of synaptic connectivity was found for both burst and tonic firing $\mathrm{CN}$ neurons (20 burst and 2 tonic). 
A

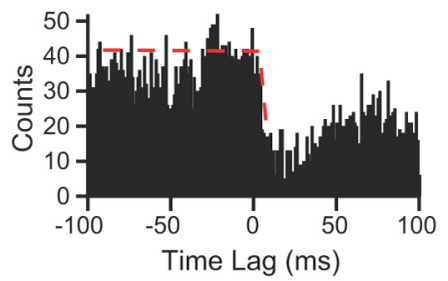

B

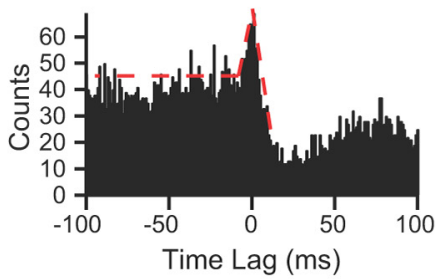

C

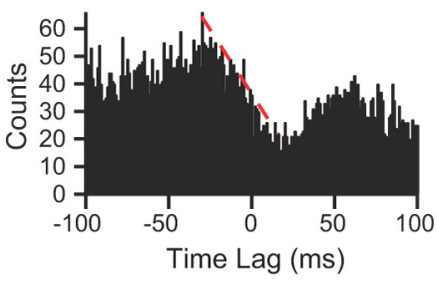

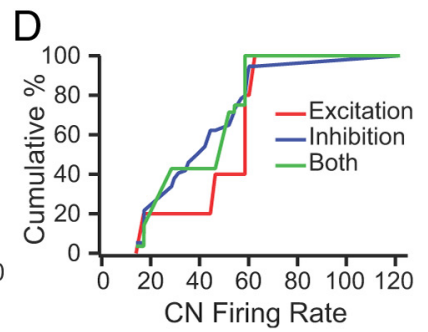

Figure 4. $\quad C S-C N$ correlograms show evidence of synaptic connections. $\boldsymbol{A}$, Evidence of monosynaptic connection between the recorded PC and CN neuron (corresponds to connectivity shown in Fig. 2A). Correlogram level is relatively flat until 1-2 ms after 0 time (time of $C S$ ) and then drops precipitously, indicating a strong inhibition caused by the $(S$ in the PC. $\boldsymbol{B}$, Correlogram showing evidence of synaptic connections to a CN neuron by both the recorded PC and a collateral of the olivocerebellar axon to same PC cell. The correlogram shows a brief excitation followed by an inhibition. C, Example of correlogram showing no evidence of a direct synaptic relationship because inhibition of activity starts well before $t=0$, as indicated by the downwardly sloped red dashed line, and there is no deflection of this general trend at any of the required latencies. $\boldsymbol{D}$, The cumulative percentage of each type of olivocerebellar axon-PC-CN synaptic connection pattern is plotted as a function of $\mathrm{CN}$ firing rate. The overlap of the three curves indicates that the probability of identifying each synaptic connectivity pattern as a function of the CN firing rate is essentially the same.

\section{Patterns of synaptic connectivity}

The basic wiring diagram of the connections between the IO, cerebellar cortex, and CN is consistent with, and indeed suggests, activation of the IO, either directly or via stimulation of its afferent pathways, will cause a sequential excitation-inhibition of $\mathrm{CN}$ activity. Indeed, such biphasic responses have been reported (Eccles et al., 1967; Llinás and Mühlethaler, 1988); however, such responses may reflect the activation of a large portion of the IO by the stimulus and convergence onto $\mathrm{CN}$ neurons, rather than a precise alignment of the projections between these areas down to the cellular level. On the other hand, anatomical studies have shown with increasing precision that the circuits between the IO cerebellum form closed loops (Voogd and Bigaré, 1980; Apps and Hawkes, 2009; Ruigrok, 2010), raising the possibility that a closed loop organization could be present down to the single-cell level.

Our results provide evidence that such precise wiring does, in fact, happen fairly commonly. Overall, the 100 CS-CN correlograms that showed evidence of synaptic connectivity reflected connections to $\mathrm{CN}$ neurons from 94 PCs (i.e., inhibitory responses) and 30 olivocerebellar axon collaterals (excitatory responses). These combined to produce pure inhibitory responses in $\mathrm{CN}$ cells in 70 cases, sequential excitatory-inhibitory responses in 24 cases, and purely excitatory responses in only 6 cases (these were weak). Thus, the dominant response of the $\mathrm{CN}$ to spontaneous olivocerebellar activity is inhibitory; however, the mixed response observed $24 \%$ of the time indicates a closed-loop organization occurs down to the single-cell level in many cases.

We determined whether the observed level of sequential excitatory-inhibitory responses is similar or higher than would be expected if axon collateral and PC connections were made independently (i.e., Is there a preferential targeting of the same $\mathrm{CN}$ cell by the involved axons?). Based on the CS-CN correlograms, the overall probability of observing an excitatory synaptic connection is 0.30 and that of observing an inhibitory connection is 0.94 . Thus, the probability of observing both connections being present if they are independent events is 0.282 , the product of individual probabilities, which is actually slightly more than what was observed (0.24). So whereas a closed-loop circuit occurs a significant percentage of the time, our data provide no evidence of a specific mechanism to favor the formation of such connections with single-cell specificity.

Last, we tested whether our ability to observe inhibitory or excitatory responses might have been influenced by the firing rates of the $\mathrm{CN}$ cells in our sample by generating cumulative summation curves for the three types of connections (Fig. $4 D)$. The probability of observing a particular type of synaptic connectivity was not strongly dependent on the firing rate of the CN cell, as shown by the similarity of the cumulative summation curves for the three types of connections. The pure inhibitory and mixed connectivity curves overlap one another, whereas the curve for excitatory connections is shifted only slightly to higher frequencies.

\section{Characteristics of CS-triggered inhibition}

Because inhibition of CN activity was generally the dominant effect of CS activity, even in the cases where excitation was present, the remainder of the paper will focus on its characteristics. To assess the strength of the inhibition caused by CS activity, we quantified several parameters of the post-CS trough in the correlograms. Of the 100 correlograms, 33 were suitable for these analyses because they had relatively flat baselines before the CS (baseline being defined as the average bin height during the 50$100 \mathrm{~ms}$ preceding the CS). These 33 correlograms were based on the activity of $8 \mathrm{CN}$ neurons and 33 PCs.

The CS's inhibitory action on CN spiking was variable but often quite strong. The nadir of the post-CS trough was determined by averaging the three lowest bins of the correlogram between the time of the CS $(t=0 \mathrm{~ms})$ and $100 \mathrm{~ms}$ later. So measured, CSs resulted in a maximal reduction of $80.0 \pm$ $22.9 \%$ (mean $\pm \mathrm{SD}$; range, $100-32 \%$ ) of the baseline $\mathrm{CN}$ activity. The latency of the minimum (the single lowest bin) was $28.1 \pm 10.9 \mathrm{~ms}$.

Overall, the duration of the inhibition (time to return to first crossing of the baseline) was $90.2 \pm 44.1 \mathrm{~ms}$. However, there appeared to be two distinct forms that the return to baseline activity levels could take. In 17 correlograms, a smooth rise to the baseline occurred (Fig. 5A). In the remaining 16 correlograms, there was a rapid initial rise toward baseline followed by a slower or delayed rise that added a long tail to the response, suggesting the presence of an additional inhibitory process beyond that of an IPSP generated by the CS (Fig. 5B). The duration of the inhibitory response for the first class of correlograms was $55.2 \pm 23.8 \mathrm{~ms}$ $(n=17)$ and that of the second class was $127.4 \pm 26.2 \mathrm{~ms}(n=$ 16). However, the slope of the rise for correlograms with a long tail could be quite shallow, and the value obtained by measuring the first crossing of the baseline probably underestimates the full extent of the inhibition (measurements by eye gave an average value of $204 \mathrm{~ms}$ ).

One possible explanation for the extended tail to the response in some correlograms is that CSs can occur rhythmically at $80-$ 120 ms intervals (Sasaki et al., 1989). Thus, if a CS occurred as part of a train of such $\sim 10 \mathrm{~Hz}$ CS activity (note that for the present purposes, we are considering even a pair of CSs with an ISI of $\sim 100 \mathrm{~ms}$ as a "train"), it could extend the inhibitory re- 
A
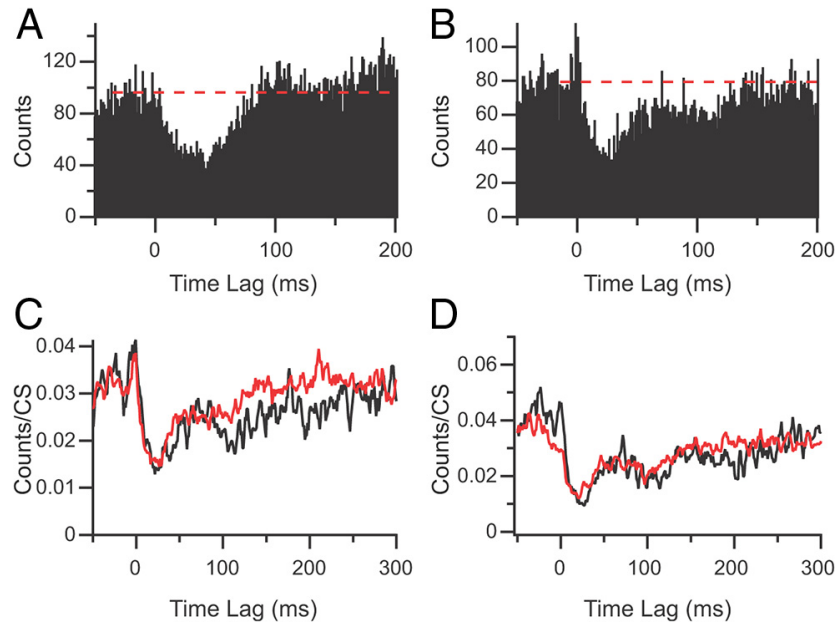

D

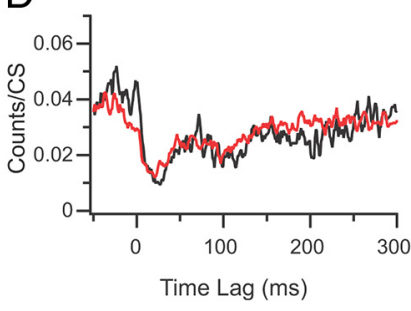

Figure 5. Inhibitory responses can exhibit distinct morphologies. $\boldsymbol{A}, \mathrm{CS}-\mathrm{CN}$ correlogram showing a pure inhibitory response that rises smoothly back to baseline (dashed line). $\boldsymbol{B}$, Correlogram showing an initial excitatory response followed by a long-duration inhibitory response. Note that there appears to be two components to the inhibitory response: an initial depression in activity that rises rapidly toward baseline and a plateau followed by an eventual return to baseline. C, D, Normalized CS-CN histograms triggered off of isolated CSs (red traces) and CSs succeeded by additional CSs within $200 \mathrm{~ms}$ (black traces). Correlograms in Care from the same $P C$ as shown in $\boldsymbol{B}$.

sponse. To investigate this possibility, CSs were sorted according to whether or not they were followed by additional CSs in the same PC during the succeeding $200 \mathrm{~ms}$. The inhibitory responses to such trains of CSs were then compared to responses associated with isolated CSs by generating CS-CN correlograms from each set of CSs. This comparison was performed for 15 of the 16 longtailed responses because the remaining one had too few CSs to subdivide into two classes. The correlograms were normalized by dividing by the number of CSs used to create them. The normalized responses were then compared by dividing them into $100 \mathrm{~ms}$ segments, starting at $0 \mathrm{~ms}$ (the time of the CS). A $100 \mathrm{~ms}$ period was chosen because it is the typical time interval between CSs when firing rhythmically. The average height of the $1 \mathrm{~ms}$ bins in each segment of the correlograms were then compared. For period $1(0-100 \mathrm{~ms}$ after $\mathrm{CS})$, no significant difference was found for all 15 cells (where the significance criterion was $p<0.05$ in a one-sided $t$ test that the bin height of the isolated CS correlogram is larger than that of the doublet one). The lack of difference in this period is expected as the second CS (in the case of CSs that were part of trains) would only occur near or after the end of this period. In periods 2 (12 of 15 PCs) and 3 (11 of 15 PCs), the bin height was significantly higher for the isolated CSs compared with the $\sim 10 \mathrm{~Hz}$ CSs in most PCs. In period 4 , only 1 of $15 \mathrm{PCs}$ showed significant differences. Figure $5 C$ shows the effect of the occurrence of additional CSs on the response. The black trace (CS-CN correlogram using train CSs) is closely aligned with the red trace (CS-CN correlogram using isolated CSs) for the first $\sim 90 \mathrm{~ms}$ after CS and then drops below the latter and takes longer to return to baseline. Nevertheless, the entire tail portion of the response cannot be attributed to additional CSs (at least to additional CSs in the same PC) because, although reduced, the tail of the response is still clearly present in the CS-train CS-CN correlogram. Moreover, in some cases, the normalized correlograms of the two CS sets were essentially identical (Fig. 5D).

To assess the significance of CS-associated inhibition further, we calculated the average number of "missing" spikes in the CN cell attributable to each CS. The number of spikes between $3 \mathrm{~ms}$ after the CS onset and the time at which the correlogram returned to baseline (first crossing) were subtracted from the expected number of spikes during this time period, the latter being calculated from the baseline of the correlogram. The difference was then normalized by the number of CSs used to make the correlogram. On average, $1.45 \pm 0.6(n=33) \mathrm{CN}$ spikes were lost per CS. Based on their average firing rates, the $\mathrm{CN}$ cells would have normally generated $2.4 \pm 0.7$ spikes during the various inhibitory periods, so the CSs were associated with $60.4 \%$ reduction in $\mathrm{CN}$ firing by this measure.

\section{Relationship of CS inhibition to overall activity levels}

Given the nonlinear membrane properties of CN neurons, it is possible that the inhibitory efficacy of CS activity might vary with the electrical state of the $\mathrm{CN}$ neuron. To investigate this issue, we determined the efficacy of each CS in inhibiting CN firing as a function of the firing rate of the $\mathrm{CN}$ cell before the CS. Thus, the baseline $\mathrm{CN}$ firing rate was computed for the period $210-10 \mathrm{~ms}$ before the CS. The CN firing rate after each CS was also calculated for the duration of the inhibitory response, as measured from the CS-CN correlogram compiled from the entire recording session, where the start of the response was taken as $3 \mathrm{~ms}$ after CS onset and the end as the first crossing of the baseline. CS trials in which the $\mathrm{CN}$ cell was silent during the baseline period were excluded from the analysis, as it was impossible to measure an inhibitory effect in these cases; however, they only represented a small minority of the trials $(0-10 \%)$. Scatter plots were then generated by plotting the baseline $\mathrm{CN}$ firing rate versus the percentage decrease in firing rate during the post-CS period (Fig. 6).

The frequency dependence of inhibitory efficacy was analyzed for 23 PCs that connected to one of $4 \mathrm{CN}$ neurons in which the CS-CN correlogram showed a pure inhibitory interaction. The strength of the inhibitory response varied considerably between cells, but in every case, the efficacy of the inhibition strengthened with increasing $\mathrm{CN}$ baseline firing rate. In general, the percentage decrease curves tended to asymptote at $-72.16 \pm 20.82 \%$ as the baseline firing rate increased. This trend may reflect, at least in part, a floor effect at lower firing rates, but it is worth noting that the trend was also found for PCs connected to the CN neuron that had the highest average firing rate in our population and for which the relative efficacy of the CS-mediated inhibition was relatively weak (Fig. 6C,D). The reduced efficacy of the CS at lower $\mathrm{CN}$ firing rates is consistent with the reduced efficacy of the CSs that occur during the inhibitory response because of a preceding CS as was shown in Figure 5, C and D. Nevertheless, it seems clear that CSs can have a major inhibitory effect on $\mathrm{CN}$ activity regardless of the initial state of the $\mathrm{CN}$ cell. It is also worth noting that the scatter plots indicate that the efficacy could vary significantly from trial to trial, even for trials with the higher baseline firing rates, implying that additional factors help determine the efficacy of the CS.

\section{CS-mediated inhibition is observable under distinct network states}

Approximately two-thirds of CS-CN correlograms in which we could identify monosynaptic connections had nonstationary baselines, as stated previously. Two examples are shown in Figure 7, $A 1$ and B1. Such baselines suggest that complex changes in network activity and/or the state of the $\mathrm{CN}$ neuron are associated with the times at which CSs occur. Given the time relationships, these fluctuations are obviously not directly caused by the CSs themselves; however, the presence of such trends raises the issue 
of the extent to which the efficacy of CS activity to inhibit $\mathrm{CN}$ neurons depends on the ongoing network activity.

To investigate this issue, we used PC-CN cell pairs whose correlograms had nonhorizontal baselines and, for each cell pair, selected a subset of its CSs in which $\mathrm{CN}$ activity was relatively stable in the time preceding each CS (for selection process, see Materials and Methods, Off-line data analysis). CS-CN correlograms generated from such CS subsets showed flat baselines (i.e., during negative time lags) in contrast to the undulating baselines of the corresponding correlograms generated from the full set of CSs (Fig. 7, $A 1$ vs $A 2, B 1$ vs $B 2)$. The selected CSs occurred throughout the recording period (Fig. $7 A 3, B 3)$ as opposed to being clustered in one period, suggesting that $\mathrm{CN}$ baseline activity varied similarly throughout the recording. The correlograms generated by the selected CSs clearly still show the presence of an inhibition of $\mathrm{CN}$ activity triggered by the CS. Moreover, the onset of the post-CS response occurs at the same times in original and flat baseline correlograms (Fig. 7, arrows). These results strengthen the conclusion that the observed post-CS depression in $\mathrm{CN}$ activity reflects a monosynaptic connection between the recorded PC and $\mathrm{CN}$ neuron and is not caused by ongoing network events that may be correlated with CS activity.

However, network activity might still influence CS efficacy. For example, given the results in Figure 6, we would expect that when $\mathrm{CN}$ activity is already undergoing some inhibitory process, the efficacy of the CS would be decreased. Thus, for CS-CN cell pairs whose correlograms had a negatively sloped baseline leading up to the CS (Fig. 7A1), we compared the percentage drop in activity from baseline to the minimum of the inhibitory trough after CS between the correlogram generated from the entire set of CSs and the correlogram generated using only the CSs selected to obtain a flat baseline (Fig. 7, A1 vs $A 2$ ).

The selected CS-CN correlograms had flat but noisy baselines, so the baseline value of these correlograms was determined by averaging the values of the bins for the $50 \mathrm{~ms}$ preceding the CS (Fig. 7A2,B2, long red horizontal lines). The value of the baseline for the CS-CN correlograms from the complete recording session was taken as the value at the inflection point indicating the onset of the CS-mediated inhibition (Fig. 7A1,B1, arrows). The minimum of the trough in the response was determined by averaging the lowest 10 bins between 0 and $100 \mathrm{~ms}$ in all correlograms (Fig. 7 , short red horizontal lines indicate minimum level). The percentage drop in activity for the stationary baseline correlograms was significantly greater than that for correlograms from the
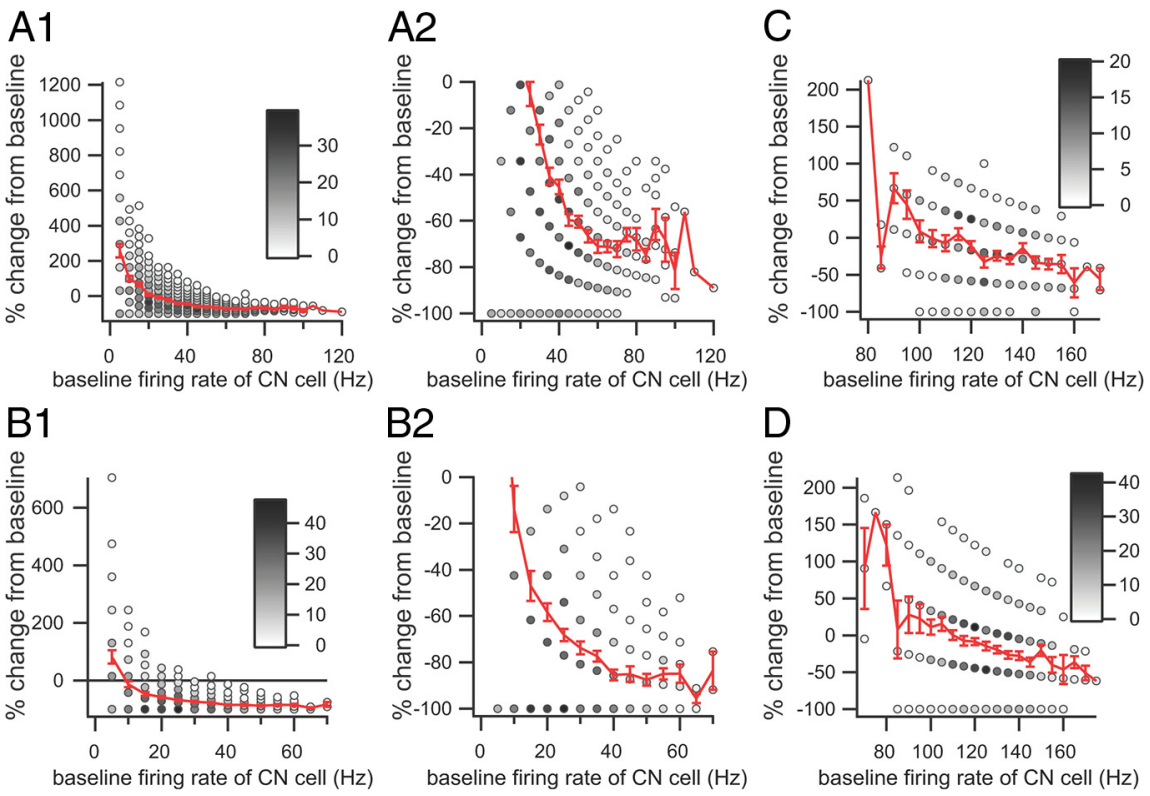

Figure 6. Dependence of CS inhibitory efficacy on CN firing rate. Scatter plots show the percentage change in the CN firing rate from baseline versus the baseline firing rate of the $C N$ neuron. $A 1, B 1, C, D$, Each plot shows the relationship between a single $P C$ value is indicated by the grayscale level of the circle interior at the point. The red curve in each plot is the average percentage change as a function of baseline $C N$ firing rate. $\boldsymbol{A 2}, \boldsymbol{B} \mathbf{2}$, A portion of the data of the plots in $\boldsymbol{A} \mathbf{1}$ and $\boldsymbol{B} \mathbf{1}$, respectively, with an expanded $\boldsymbol{y}$-axis.

A1

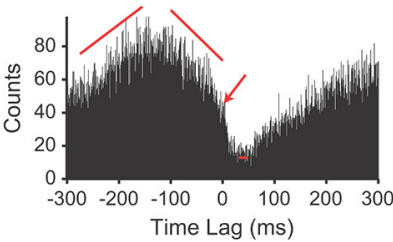

B1

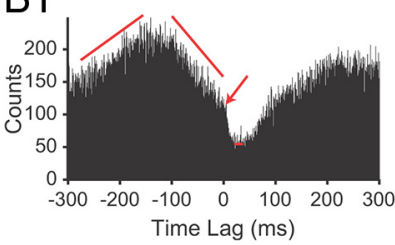

Figure 7. Detection of CS-mediated inhibition does not require CN neurons to be in specific state of excitability. A1, B1, Two examples of CS-CN correlograms in which a CS-mediated inhibition of CN activity is superimposed on an ongoing change in the firing level of the CN neuron. Arrows indicate the onset of CS-mediated inhibition. A2, B2, CS-CN correlograms generated by using a subset of the CSs used to create correlograms in $\boldsymbol{A} 1$ and $\boldsymbol{B}$ 1. Subsets chosen by selecting CSs for which the CN exhibited stable firing over the two ranges indicated by the slanted red lines in $\boldsymbol{A} \mathbf{1}$ and $\boldsymbol{B} \mathbf{1}$. Long red horizontal lines indicate average level of the baseline and the bins over which the averaging was done. Short red horizontal lines indicate the minimum level of trough in the response as determined by averaging 10 lowest bins between 0 and $100 \mathrm{~ms}$. Bin size, $1 \mathrm{~ms}$. A3, B3, Raster displays showing times of the subset of selected CSs from the entire 20 min recording session that were used to generate the correlograms in $\boldsymbol{A} \mathbf{2}$ and $\mathbf{B 2}$. complete data set (complete, $54.4 \pm 17.3 \%$; stationary, $79.8 \pm$ $15.9 \% ; n=7$ CS-CN cell pairs, 2 experiments; $p=0.0002$, paired $t$ test).

\section{Nonsynchronous CS activity can inhibit $\mathrm{CN}$ activity}

In the present study, we are mainly concerned with demonstrating that CS activity can directly influence the activity of CN neurons, not with the underlying mechanism(s) by which it does so. However, because CSs are often synchronized on a millisecond time scale, the question arises as to whether the CS activity of an individual PC can significantly alter the activity of a CN neuron, 

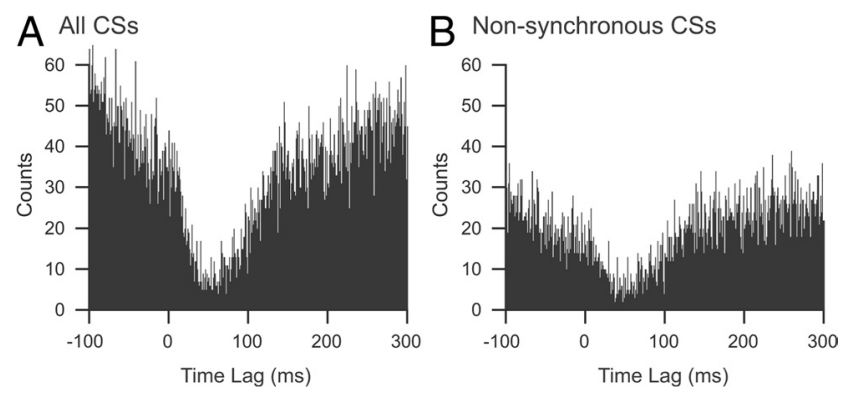

Figure 8. Nonsynchronous CSs can inhibit CN activity. CS-CN correlograms compiled using either all CSs recorded from one $P C(A)$ or only those CSs that were not synchronized with CSs in any of the other $29 \mathrm{PCs}$ that were simultaneously recorded $(\boldsymbol{B})$. To obtain the subset of nonsynchronous $C S$ s, the spike train was compared with those of the other recorded PCs, and any spikes that occurred at the same millisecond were removed. This resulted in removal of $44 \%$ of the CSs in this PC. The recording session was $20 \mathrm{~min}$.

or whether the effects detected in the CS-CN correlograms are the solely the result of synchronized CS activity across populations of PCs that converge onto the same CN neuron.

To address this question, we investigated whether CSassociated inhibition could be detected when CS activity was in a relatively desynchronized state. We assume that variations in the level of synchronous CS activity in the recording array are a good measure of the synchronization state of the PC population. Thus, all CSs that occurred synchronously with any other CS in the array, where "synchronously" is defined as the onset of two spikes occurring in the same millisecond, were removed from the spike trains. CS-CN correlograms were then generated from the remaining nonsynchronous CSs to determine whether the inhibitory effect observed using the entire set of CSs was still present. This was done for 35 synaptically connected PC-CN cell pairs from six animals. In general, an inhibitory effect was still clearly present, although often its strength was reduced (still present, 27 cell pairs; not present, 6 pairs; correlogram too sparse to judge relationship, 2 pairs). The correlograms in Figure 8 are from a $\mathrm{PC}-\mathrm{CN}$ cell pair in which nonsynchronous CS activity produced a similar, but somewhat weaker, inhibition of $\mathrm{CN}$ activity to that produced by all of the CSs. Nevertheless, a clear inhibitory effect is still present, suggesting that CSs can have a significant effect even when not highly synchronized, but that synchronization is a mechanism by which CS activity may enhance its efficacy.

\section{Physiologically identified synaptic relationships are consistent with topography of $\mathrm{PC}-\mathrm{CN}$ pathway}

In each experiment, the position of the last recorded $\mathrm{CN}$ cell was marked by an injection of dye (see Materials and Methods). Figure 9 shows the locations of all such cells that were identified on histological sections. In Figure 9, the black circles indicate cells in which no monosynaptic connection from a PC or olivocerebellar axon collateral was identified by correlogram analysis, whereas the red circles indicate $\mathrm{CN}$ cells in which monosynaptic connections were found. All of the CN cells for which synaptic connections were found fell within regions to which crus $2 \mathrm{a}$ has been shown to project (Sugihara et al., 2009). In particular, based on their locations, cells a-c were likely innervated by PCs in zebrin compartment 6- and cell d by PCs from compartment 5- (Sugihara et al., 2009). In contrast, the distribution of cells that did not have synaptic connections with the PCs being recorded is more widespread. It is not surprising, but still worth noting, that a number of CN cells within the crus 2 projection region did not show evidence of synaptic connections to the recorded PCs. This

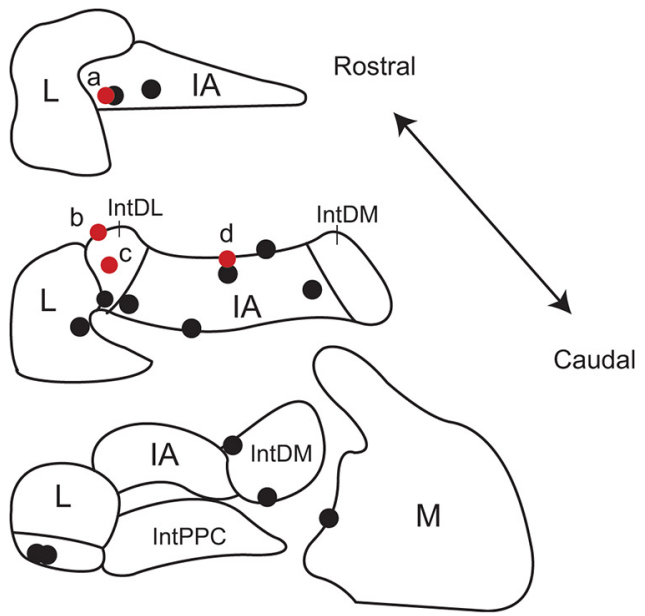

Figure 9. Locations of recorded $\mathrm{CN}$ neurons. Locations of $\mathrm{CN}$ neurons with (red circles) and without (black circles) synaptic input from recorded crus 2a PCs as identified by analysis of CS-CN correlograms. Schematics of coronal sections of CN based on the atlas of Paxinos and Watson (1998) are shown. IA, Interpositus anterior; IntDL, dorsolateral division of interpositus; IntDM, dorsomedial division of interpositus; IntPPC, posterior parvicellular division of interpositus; L, lateral nucleus; $M$, medial nucleus.

is to be expected as our electrode array only records from 2 to $3 \%$ of the PCs in the area of the array $\left(1.7 \mathrm{~mm}^{2}\right)$, based on a PC density of $900-1200 / \mathrm{mm}^{2}$ (Armstrong and Schild, 1970) and that the recording array only covers a portion of the apex of crus $2 \mathrm{a}$. That we actually found synaptic connections for 4 of 11 histologically identified $\mathrm{CN}$ cells within the crus 2 projection area is almost certainly attributable to the large amount of convergence in the PC to CN pathway.

\section{Discussion}

This study reports the first simultaneous recordings made in vivo from PCs and CN neurons demonstrated to be synaptically connected. Spontaneous CSs were found to exert a powerful inhibitory effect on their postsynaptic CN neurons. CS activity was also used to infer that olivocerebellar axon collaterals produce a weak excitatory effect on $\mathrm{CN}$ neurons. Our results also suggest that a significant fraction of $\mathrm{CN}$ neurons receive monosynaptic excitation from collaterals of the same olivary axon that disynaptically inhibits it via a PC, resolving the alignment of circuitry between the cerebellar cortex and nuclei down to the single-cell level.

\section{Methodological considerations}

Correlogram analysis is the standard electrophysiological method for identifying synaptic connectivity (Perkel et al., 1967; Aertsen et al., 1989; Csicsvari et al., 1998), and the correlogram patterns observed here (e.g., Figs. $4 A, B, 5,7$ ) are consistent with monosynaptic linkages from PCs and/or olivocerebellar axon collaterals to $\mathrm{CN}$ neurons. However, correlograms of spontaneous activity cannot provide evidence of causality, and so, by themselves, cannot be proof of a unique underlying connectivity pattern. To conclude that we have correctly identified the underlying connectivity, it is necessary to rule out plausible alternatives and provide additional corroborating evidence.

With regard to the cerebellar cortex, the criteria used to identify synaptic connections (latency and direction of the response), combined with the known anatomy of cerebellar circuits, essentially limit the set of plausible underlying circuits to two possibilities: the circuits we want to infer, namely monosynaptic linkages between a PC and/or its climbing fiber and a CN cell, and one set 
of alternatives attributable to branching of olivocerebellar axons to multiple PCs (Fig. 3D). However, the latter case still represents the synaptic influence of CSs on a CN neuron (just not those generated by the PC being recorded) and so is essentially a distinction without a difference for the main issue at hand: the effect of CSs on CN neurons.

Another possibility is that intra-CN circuits are activated in precise temporal registry with CSs. For example, local inhibitory interneurons could be activated by olivary axon collaterals, either directly or indirectly. There is little evidence consistent with this scenario, and some against it. Almost all (>95\%) CN neurons are projection neurons (McCrea et al., 1978), suggesting that interneurons are not a major synaptic force in the CN. Furthermore, evidence suggests that intrinsic inhibitory processes are minimal in the CN (Uusisaari and Knopfel, 2008). Last, olivocerebellar collaterals provide a small percentage of the input to the CN (Van Der Want et al., 1989), making it implausible that they, acting via a minimally disynaptic pathway, would have an effect that was larger than, and as precisely timed as, that of the PCmediated inhibition.

Histological evidence (Fig. 9) supports our interpretation of the correlogram patterns. All CN cells that had physiologically identified synaptic connections from crus 2 PCs and whose location was histologically identified were found within the crus 2 projection region based on the results of Sugihara et al. (2009). In summary, the lack of plausible alternatives, and the histological evidence, support the conclusion that the observed CS-CN correlogram patterns reflect monosynaptic connections between PCs and CN neurons and between olivocerebellar axon collaterals and $\mathrm{CN}$ neurons.

A second methodological issue is the use of ketamine/xylazine anesthesia. However, it is unlikely that the relationships observed here are peculiar to this anesthetic regimen. The PC-CN synapse is GABAergic, and neither anesthetic alters the properties of GABAergic transmission significantly. Moreover, CS firing rates and synchrony patterns are similar under ketamine and in awake animals (Lang et al., 1999), as are SS (Marshall and Lang, 2009) and $\mathrm{CN}$ firing rates. Thus, the outflow from the PCs and the overall excitability of the $\mathrm{CN}$ neurons are similar to what they are under physiologic conditions. One potentially significant difference is that the $\mathrm{CN}$ neurons show spontaneous burst firing patterns more often under anesthesia than in awake animals. However, such patterns do occur spontaneously in nonanesthetized animals (Steriade et al., 1971; Palmer, 1979), and frequently during behavior (Thach, 1968; Grimm and Rushmer, 1974; Armstrong and Edgley, 1984a; Fuchs et al., 1993). Moreover, similar effects of CS activity were observed for both burst and tonic firing $\mathrm{CN}$ neurons. One additional potentially important difference from the awake state is that the variability of SS activity may be less under anesthesia, and this has been proposed as an important factor in PC-CN synaptic communication (Hoebeek et al., 2005). Nevertheless, although these various factors may result in some quantitative changes in the inhibitory effects we observed, they are unlikely to change the basic qualitative result that CSs cause a significant inhibitory effect on CN activity.

\section{Spontaneous CSs inhibit CN activity}

Our basic finding, that spontaneous CSs have a net inhibitory effect on CN neurons, cannot simply be deduced from the fact that PCs are GABAergic (Ito and Yoshida, 1966; Ito et al., 1970), partly because of the interactions between SSs and CSs. Indeed, as mentioned previously, CSs are generally assumed to make no significant direct contribution to PC output, but rather to act only via long- or short-term effects on SS activity. Our results have no direct bearing on the first possibility, but with regard to short-term effects, they are inconsistent with the main effect of a CS being caused by the subsequent pause in SSs, because then we should have observed an excitatory response after the CS. In contrast, in all correlograms showing evidence of a monosynaptic $\mathrm{PC}-\mathrm{CN}$ connection, $\mathrm{CN}$ activity decreased after the CS, even when there was an initial excitation that preceded it.

The long duration of the CS-triggered inhibition (range, 35$270 \mathrm{~ms}$ ) we observed requires some explanation. Previous in vivo recordings found that stimulation of the cerebellar cortex evoked 50- to 100-ms-long IPSPs (Ito and Yoshida, 1966); however, this was under barbiturate anesthesia, which prolongs GABA $_{\mathrm{A}}$ IPSPs (Thompson and Gahwiler, 1992). In slices, stimulus-evoked and spontaneous IPSPs were all $<100 \mathrm{~ms}$ (Jahnsen, 1986b). Moreover, in vivo, where ongoing synaptic activity should result in a shorter membrane time constant, IPSP duration should be reduced and more closely match the underlying IPSC, and virtually all GABAergic IPSCs in CN neurons are $<40 \mathrm{~ms}$ (Pedroarena and Schwarz, 2003; Uusisaari and Knopfel, 2008). The lower part of our response range fits well with these IPSC time courses; however, most of our responses, particularly the largeamplitude ones, were significantly longer, suggesting that the response to the $\mathrm{CS}$ comprises more than a simple $\mathrm{GABA}_{\mathrm{A}}$ IPSP. The existence of a second component is also suggested by the biphasic return to baseline in half of the correlograms showing CS-mediated inhibition.

Part of this extended duration reflects the occurrence of additional CSs at latencies $<200 \mathrm{~ms}$. However, such repetitive firing cannot fully explain the extended time course of the inhibition. Thus, we suggest that it may result from an interaction of the IPSP with the intrinsic membrane properties of $\mathrm{CN}$ neurons. In particular, $\mathrm{CN}$ neurons have a plateau potential, which allows them to exhibit sustained firing and the termination of which appears to require strong inhibition (Jahnsen, 1986a,b). If CS-mediated inhibition breaks this plateau, it could switch the CN cell into a less excitable state for a period that extends beyond the duration of the GABAergic IPSP, leading to the long-tailed responses in some of the correlograms.

\section{How can CSs produce a significant inhibitory effect in the presence of SSs?}

Given that CSs significantly affect CN activity, the question immediately arises as to how this is possible when they are embedded in a sea of SSs. Even in behavioral paradigms where strong CS modulation is observed (Graf et al., 1988), the variation in firing rate is, at most, $1-2 \mathrm{~Hz}$, whereas SS rates average $30-50 \mathrm{~Hz}$, and may modulate from 0 to $\sim 200 \mathrm{~Hz}$. Two characteristics of CS activity suggest possible answers.

The CS often triggers multiple axonic spikes (Ito and Simpson, 1971; Khaliq and Raman, 2005; Monsivais et al., 2005), which conceivably could exert a stronger, and possibly qualitatively different, influence on a $\mathrm{CN}$ neuron than the individual axonic spike associated with an SS, particularly given the nonlinear membrane properties of $\mathrm{CN}$ neurons. Consistent with this idea, cerebellar cortical stimuli that simulate CS bursts break the plateau potential of $\mathrm{CN}$ neurons, whereas stimuli that simulate SSs do not (Jahnsen, 1986b). If the burst nature of the CS does underlie its efficacy, then a recent report showing that the number of spikelets comprising a CS varies between cerebellar cortical zones (Paukert et al., 2010) raises the intriguing possibility that the inhibitory control of the olivocerebellar system over different regions of the $\mathrm{CN}$ varies. However, in many PCs (43\%), each CS 
apparently results in only a single spike being propagated down the axon (Ito and Simpson, 1971), making it indistinguishable, from the perspective of the CN neuron, from an SS. For these PCs, CSs would comprise an insignificant minority of the PC output.

A more general mechanism that could allow a CN cell to distinguish SSs and CSs is suggested by (1) the synchronization of CSs among PCs in narrow bands oriented parallel to the transverse folial axis (Bell and Kawasaki, 1972; Llinás and Sasaki, 1989; Sugihara et al., 1993; Lang et al., 1999), (2) the correspondence in many cases of the synchrony bands to the zebrin compartments (Sugihara et al., 2007), and (3) the convergence of PC axons from each zebrin staining-defined compartment to a circumscribed CN region (Voogd and Ruigrok, 2004; Pijpers et al., 2005; Sugihara et al., 2009). Thus, each $\mathrm{CN}$ neuron could receive synchronous CSs from the large number of PCs that converge onto each $\mathrm{CN}$ neuron. Indeed, synchronous CS activity is associated with the ends of CN firing bursts (T. A. Blenkinsop and E. J. Lang, unpublished data). The physiological relevance of this mechanism is suggested by the fact that changes in CS synchrony are associated with several different motor behaviors (Welsh et al., 1995; Mukamel et al., 2009; Ozden et al., 2009).

In conclusion, by recording from synaptically connected $\mathrm{PC}-\mathrm{CN}$ cell pairs in vivo, we have provided evidence that CS activity is an important factor in the control of $\mathrm{CN}$ activity.

\section{References}

Aertsen AM, Gerstein GL, Habib MK, Palm G (1989) Dynamics of neuronal firing correlation: modulation of "effective connectivity." J Neurophysiol 61:900-917.

Apps R, Hawkes R (2009) Cerebellar cortical organization: a one-map hypothesis. Nat Rev Neurosci 10:670-681.

Armstrong DM, Edgley SA (1984a) Discharges of nucleus interpositus neurones during locomotion in the cat. J Physiol 351:411-432.

Armstrong DM, Edgley SA (1984b) Discharges of Purkinje cells in the paravermal part of the cerebellar anterior lobe during locomotion in the cat. J Physiol 352:403-424.

Armstrong DM, Schild RF (1970) A quantitative study of the Purkinje cells in the cerebellum of the albino rat. J Comp Neurol 139:449-456.

Bell CC, Kawasaki T (1972) Relations among climbing fiber responses of nearby Purkinje cells. J Neurophysiol 35:155-169.

Bengtsson F, Ekerot CF, Jorntell H (2011) In vivo analysis of inhibitory synaptic inputs and rebounds in deep cerebellar nuclear neurons. PLoS One 6:e18822.

Blenkinsop TA, Lang EJ (2006) Block of inferior olive gap junctional coupling decreases Purkinje cell complex spike synchrony and rhythmicity. J Neurosci 26:1739-1748.

Bloedel JR, Roberts WJ (1971) Action of climbing fibers in cerebellar cortex of the cat. J Neurophysiol 34:17-31.

Buisseret-Delmas C, Angaut P (1993) The cerebellar olivo-corticonuclear connections in the rat. Prog Neurobiol 40:63-87.

Crill WE (1970) Unitary multiple-spiked responses in cat inferior olive nucleus. J Neurophysiol 33:199-209.

Csicsvari J, Hirase H, Czurko A, Buzsaki G (1998) Reliability and state dependence of pyramidal cell-interneuron synapses in the hippocampus: an ensemble approach in the behaving rat. Neuron 21:179-189.

Davie JT, Clark BA, Hausser M (2008) The origin of the complex spike in cerebellar Purkinje cells. J Neurosci 28:7599-7609.

De Zeeuw CI, Berrebi AS (1995) Postsynaptic targets of Purkinje cell terminals in the cerebellar and vestibular nuclei of the rat. Eur J Neurosci 7:2322-2333.

Eccles JC, Ito M, Szentágothai J (1967) The cerebellum as a neuronal machine. Berlin: Springer.

Fuchs AF, Robinson FR, Straube A (1993) Role of the caudal fastigial nucleus in saccade generation. I. Neuronal discharge patterns. J Neurophysiol 70:1723-1740.

Graf W, Simpson JI, Leonard CS (1988) Spatial organization of visual messages of the rabbit's cerebellar flocculus. II. Complex and simple spike responses of Purkinje cells. J Neurophysiol 60:2091-2121.
Granit R, Phillips CG (1956) Excitatory and inhibitory processes acting upon individual Purkinje cells of the cerebellum in cats. J Physiol 133:520-547.

Grimm RJ, Rushmer DS (1974) The activity of dentate neurons during an arm movement sequence. Brain Res 71:309-326.

Hoebeek FE, Stahl JS, van Alphen AM, Schonewille M, Luo C, Rutteman M, van den Maagdenberg AM, Molenaar PC, Goossens HH, Frens MA, De Zeeuw CI (2005) Increased noise level of Purkinje cell activities minimizes impact of their modulation during sensorimotor control. Neuron 45:953-965.

Ito M, Simpson JI (1971) Discharges in Purkinje cell axons during climbing fiber activation. Brain Res 31:215-219.

Ito M, Yoshida M (1966) The origin of cerebellar-induced inhibition of Deiters neurones. I. Monosynaptic initiation of the inhibitory postsynaptic potentials. Exp Brain Res 2:330-349.

Ito M, Yoshida M, Obata K, Kawai N, Udo M (1970) Inhibitory control of intracerebellar nuclei by the Purkinje cell axons. Exp Brain Res 10:64-80.

Jahnsen H (1986a) Electrophysiological characteristics of neurones in the guinea-pig deep cerebellar nuclei in vitro. J Physiol 372:129-147.

Jahnsen H (1986b) Extracellular activation and membrane conductances of neurones in the guinea-pig deep cerebellar nuclei in vitro. J Physiol 372:149-168.

Khaliq ZM, Raman IM (2005) Axonal propagation of simple and complex spikes in cerebellar Purkinje neurons. J Neurosci 25:454-463.

Lang EJ, Sugihara I, Welsh JP, Llinás R (1999) Patterns of spontaneous Purkinje cell complex spike activity in the awake rat. J Neurosci $19: 2728-2739$.

Llinás R, Mühlethaler M (1988) Electrophysiology of guinea-pig cerebellar nuclear cells in the in vitro brain stem-cerebellar preparation. J Physiol 404:241-258.

Llinás R, Nicholson C (1971a) Field potentials in the alligator cerebellum and theory of their relationship to Purkinje cell dendritic spikes. J Neurophysiol 34:509-531.

Llinás R, Nicholson C (1971b) Electrophysiological properties of dendrites and somata in alligator Purkinje cells. J Neurophysiol 34:532-551.

Llinás R, Sasaki K (1989) The functional organization of the olivo-cerebellar system as examined by multiple Purkinje cell recordings. Eur J Neurosci 1:587-602.

Llinás R, Sugimori M (1980a) Electrophysiological properties of in vitro Purkinje cell somata in mammalian cerebellar slices. J Physiol 305:171-195.

Llinás R, Sugimori M (1980b) Electrophysiological properties of in vitro Purkinje cell dendrites in mammalian cerebellar slices. J Physiol 305:197-213.

Llinás R, Yarom Y (1981) Electrophysiology of mammalian inferior olivary neurones in vitro. Different types of voltage-dependent ionic conductances. J Physiol 315:549-567.

Marshall SP, Lang EJ (2009) Local changes in the excitability of the cerebellar cortex produce spatially restricted changes in complex spike synchrony. J Neurosci 29:14352-14362.

McCrea RA, Bishop GA, Kitai ST (1978) Morphological and electrophysiological characteristics of projection neurons in the nucleus interpositus of the cat cerebellum. J Comp Neurol 181:397-420.

McDevitt CJ, Ebner TJ, Bloedel JR (1982) The changes in Purkinje cell simple spike activity following spontaneous climbing fiber inputs. Brain Res 237:484-491.

Monsivais P, Clark BA, Roth A, Häusser M (2005) Determinants of action potential propagation in cerebellar Purkinje cell axons. J Neurosci 25:464-472.

Mukamel EA, Nimmerjahn A, Schnitzer MJ (2009) Automated analysis of cellular signals from large-scale calcium imaging data. Neuron 63:747-760.

Ozden I, Sullivan MR, Lee HM, Wang SS (2009) Reliable coding emerges from coactivation of climbing fibers in microbands of cerebellar Purkinje neurons. J Neurosci 29:10463-10473.

Palkovits M, Mezey E, Hamori J, Szentagothai J (1977) Quantitative histological analysis of the cerebellar nuclei in the cat. I. Numerical data on cells and on synapses. Exp Brain Res 28:189-209.

Palmer C (1979) Interpositus and fastigial unit activity during sleep and waking in the cat. Electroencephalogr Clin Neurophysiol 46:357-370.

Paukert M, Huang YH, Tanaka K, Rothstein JD, Bergles DE (2010) Zones of 
enhanced glutamate release from climbing fibers in the mammalian cerebellum. J Neurosci 30:7290-7299.

Paxinos G, Watson C (1998) The rat brain in stereotaxic coordinates, Ed 4. Sydney: Academic.

Pedroarena CM, Schwarz C (2003) Efficacy and short-term plasticity at GABAergic synapses between Purkinje and cerebellar nuclei neurons. J Neurophysiol 89:704-715.

Perkel DH, Gerstein GL, Moore GP (1967) Neuronal spike trains and stochastic point processes. II. Simultaneous spike trains. Biophys J 7:419-440.

Pijpers A, Voogd J, Ruigrok TJ (2005) Topography of olivo-cortico-nuclear modules in the intermediate cerebellum of the rat. J Comp Neurol 492:193-213.

Robinson FR, Fuchs AF (2001) The role of the cerebellum in voluntary eye movements. Annu Rev Neurosci 24:981-1004.

Rowland NC, Jaeger D (2005) Coding of tactile response properties in the rat deep cerebellar nuclei. J Neurophysiol 94:1236-1251.

Ruigrok TJ (2011) Ins and outs of cerebellar modules. Cerebellum. 10:464-474.

Sasaki K, Bower JM, Llinas R (1989) Multiple Purkinje cell recording in rodent cerebellar cortex. Eur J Neurosci 1:572-586.

Sastry BR, Morishita W, Yip S, Shew T (1997) Gaba-ergic transmission in deep cerebellar nuclei. Prog Neurobiol 53:259-271.

Schild RF (1970) On the inferior olive of the albino rat. J Comp Neurol 140:255-260.

Steriade M, Apostol V, Oakson G (1971) Control of unitary activities in cerebellothalamic pathway during wakefulness and synchronized sleep. J Neurophysiol 34:389-413.

Stuart G, Hausser M (1994) Initiation and spread of sodium action potentials in cerebellar Purkinje cells. Neuron 13:703-712.

Sugihara I, Lang EJ, Llinás R (1993) Uniform olivocerebellar conduction time underlies Purkinje cell complex spike synchronicity in the rat cerebellum. J Physiol 470:243-271.

Sugihara I, Marshall SP, Lang EJ (2007) Relationship of complex spike syn- chrony to the lobular and longitudinal aldolase $\mathrm{C}$ compartments in crus IIA of the cerebellar cortex. J Comp Neurol 501:13-29.

Sugihara I, Fujita H, Na J, Quy PN, Li BY, Ikeda D (2009) Projection of reconstructed single Purkinje cell axons in relation to the cortical and nuclear aldolase C compartments of the rat cerebellum. J Comp Neurol 512:282-304

Thach WT (1968) Discharge of Purkinje and cerebellar nuclear neurons during rapidly alternating arm movements in the monkey. J Neurophysiol 31:785-797.

Thach WT (1970) Discharge of cerebellar neurons related to two maintained postures and two prompt movements. II. Purkinje cell output and input. J Physiol 33:537-546.

Thompson SM, Gahwiler BH (1992) Effects of the GABA uptake inhibitor tiagabine on inhibitory synaptic potentials in rat hippocampal slice cultures. J Neurophysiol 67:1698-1701.

Uusisaari M, Knopfel T (2008) GABAergic synaptic communication in the GABAergic and non-GABAergic cells in the deep cerebellar nuclei. Neuroscience 156:537-549.

Van Der Want JJL, Wiklund L, Guegan M, Ruigrok T, Voogd J (1989) Anterograde tracing of the rat olivocerebellar system with phaseolus vulgaris leucoagglutinin (PHA-L). Demonstration of climbing fiber collateral innervation of the cerebellar nuclei. J Comp Neurol 288:1-18.

Voogd J, Bigaré F (1980) Topographical distribution of olivary and corticonuclear fibers in the cerebellum. A review. In: The inferior olivary nucleus: anatomy and physiology (Courville J, de Montigny C, Lamarre Y, eds), pp 207-234. New York: Raven.

Voogd J, Ruigrok TJ (2004) The organization of the corticonuclear and olivocerebellar climbing fiber projections to the rat cerebellar vermis: the congruence of projection zones and the zebrin pattern. J Neurocytol 33:5-21

Welsh JP, Lang EJ, Sugihara I, Llinás R (1995) Dynamic organization of motor control within the olivocerebellar system. Nature 374:453-457.

Zar JH (1999) Biostatistical analysis, Ed 4. Upper Saddle River, NJ: Prentice Hall. 